\title{
“A FAVELA ESTÁ PASSANDO A MENSAGEM" - CONSTRUÇÕES DE NOVAS NARRATIVAS NO COMPLEXO DO ALEMÃO
}

\author{
Natã Neves do Nascimento*
}

Resumo: Esse artigo se propõe a refletir sobre a construção de novas narrativas dentro do conjunto de favelas do Complexo do Alemão e a forma como essa construção afeta os poetas e consequentemente o público presente no slam. Busco apresentar o Slam Laje que tem acontecido no Alemão através da minha experiência no campo que aconteceu no aniversário de 1 ano do evento. O Slam é um novo fenômeno da poesia oral e através de sua performance vem ganhando espaço em todo o País, através de suas batalhas os poetas da favela estão mandando o papo reto falando sobre racismo, homofobia e feminismo buscando a reflexão por parte do público. Serão analisados nesse trabalho alguns conceitos de identidade e representatividade a partir de estudos de Gloria Anzaldúa, Gayatri Spivak e Walter Benjamim.

Palavras-chave: Slam; Favela; Juventudes; Poesia.

\section{SLAM - BATALHA DE POESIA}

O poetry slam foi criado em meados da década de 1980 em Chicago nos Estados Unidos, e surge através de uma proposta de unir a poesia falada junto à performance. Marc Kelly Smith foi o idealizador desse movimento cultural e poético; na época ele era um trabalhador da construção civil e poeta, que conseguiu transformar esse evento em um grande movimento que, desde então, tem alcançado muitas pessoas. Segundo Roberta Estrela D’Alva (2011:PAG 120), era uma “tentativa de popularização da poesia falada em contraponto aos fechados e assépticos circuitos acadêmicos".

A palavra slam é uma onomatopéia da língua inglesa e indica o som de algo como se fosse uma "batida" de porta ou de janela, essa palavra é utilizada também para se referir às finais de torneios de baseball e tênis, por exemplo. Foi Smith quem nomeou de slam os campeonatos de performances poéticas que organizava, esses campeonatos se iniciaram em um bar de jazz em Chicago, porém, se expandiu de forma que ocorriam apenas no bar, mas também nas periferias da cidade.

Através da força desse movimento, um novo cenário foi aberto, propício à criação de novas performances artísticas que usam a palavra como modo de expressão daquilo que

\footnotetext{
* Pontifícia Universidade Católica do Rio de Janeiro, R. Marquês de São Vicente, 225 - Gávea, Rio de Janeiro - Rio de Janeiro, 22541-041, Brasil. E-mail: nataoneves@hotmail.com .

(iD) https:// orcid.org/0000-0003-4408-8991
} 
antes era apenas sentido. Dentre estas performances está o slam, um tipo de sarau que ocorre nos moldes de batalha de poesias.

O slam é uma competição de poesias faladas cujas performances tratam de temas sociais nas quais os poetas ou slammers, como também são conhecidos, são avaliados não por um júri técnico ou específico, mas pelo próprio público. Essa competição no Brasil acontece nas ruas e na maioria das vezes em territórios periféricos, sua composição é majoritariamente de jovens não universitários que não carregam consigo uma preocupação com as normas cultas ou até mesmo com as regras gramaticais, sua preocupação é passar sua mensagem ou "dar o papo", afinal é o público quem vai decidir quem será o(a/x) vencedor $(\mathrm{a} / \mathrm{x})$.

A competição tem um público feminino maior comparado a presença do público masculino, isso se reflete nas batalhas quando as poetas apresentam em seus versos palavras como resistência, luta e perseverança. O slam é o encontro no espaço livre em que a juventude periférica, negra, LGBT se reúne também nas praças para falar das questões que não encontram espaços em outros lugares.

Essa competição faz parte de um campeonato que tem suas divisões locais, estaduais e nacional, que vale uma vaga para o mundial na Copa do Mundo de Poesia que acontece em Paris. É preciso compreender que cada slam realiza suas competições de acordo com sua programação, os vencedores de cada edição competem em uma final, essa data da final fica a critério do grupo responsável pelo slam, o vencedor avança para o campeonato estadual e quem vence o estadual representa seu estado na competição nacional que acontece em dezembro de cada ano, mais conhecido como Slam BR. O vencedor do campeonato nacional representa o Brasil no Slam Mundo, que acontece em Paris no início de cada ano.

Como qualquer outro campeonato, o slam possui regras, e apesar de acontecerem diferentes competições pelo país, as regras, na grande maioria deles, são as mesmas. Em se tratando dos poemas, eles podem ser sobre qualquer assunto e em qualquer estilo. Porém, é importante que cada poeta apresente poemas originais de sua autoria e as apresentações não devem ultrapassar três minutos de duração. Cada participante tem direito a alguns segundos para adaptar o microfone e o palco. O tempo começa a ser contado a partir do momento em que o poeta se dirige ao público, depois dos três minutos, penalidades de tempo serão aplicadas de acordo com os segundos além dos 3 minutos de apresentação. $\mathrm{O}$ anúncio de penalidades é feito pelo apresentador depois que os juízes tiverem atribuído as notas da apresentação do poeta. 
O apresentador exerce um papel fundamental na programação do slam, ele deve anunciar ao público o nome e uma pequena descrição de cada poeta. Ele também deverá fazer a escolha dos jurados e pedir ao final de cada apresentação que eles falem suas notas. Ele tem a função de fazer o evento seguir o cronograma e incentivar o público ali presente. São escolhidos cinco jurados entre os membros da plateia, essa escolha dos jurados é feita de forma aleatória pelo apresentador um pouco antes da competição começar. A ideia dessa escolha aleatória dos jurados parte do princípio de que todo indivíduo é capaz de emitir uma opinião válida sobre arte e para isso não seria necessária uma formação acadêmica ou técnica para isso. Então, uma vez escolhidos eles devem estar atentos às apresentações e no momento solicitado informarem a nota equivalente àquela apresentação.

Os juízes darão notas de 0 a 10, com a maior nota sendo 10, para cada poema. Eles são instruídos a usar uma casa decimal para reduzir as possibilidades de empate entre os competidores. Cada poema receberá cinco notas, a mais alta e a mais baixa serão descartadas e as três restantes serão somadas, representando a nota final do poeta. Além dos jurados também é escolhida entre o público uma pessoa para ficar responsável por cronometrar as apresentações, além de contabilizar as notas informadas pelo júri.

Não é permitido o uso de auxílios visuais ou fantasias pelo poeta durante sua apresentação, essa regra de auxílios visuais tem o intuito de manter o foco nas palavras e na apresentação em si e não em objetos. Além disso, não é permitida a repetição de poemas, cada poema pode ser usado uma única vez durante as eliminatórias e uma vez na grande final.

Alguns slams dividem as suas programações com os momentos da competição e do microfone aberto, esse seria o espaço para qualquer um que está ali presente dar o seu recado e se apresentar, seja com poesias originais ou não. Esse é um momento que pode ocorrer antes ou depois da competição, sendo a ordem escolhida de acordo com o grupo responsável pelo slam.

No Brasil, o movimento dos Slams foi trazido por Roberta Estrela D’Alva (2014), atriz-MC, pesquisadora e poetisa, em meados dos anos 2000, mais especificamente em dezembro de 2008, após voltar de viagem, foi quando a artista se deu conta que esse movimento, que já era bastante conhecido nos Estado Unidos, ainda não existia no Brasil. O ZAP! Slam quer dizer "Zona autônoma da Palavra", através de um projeto que estava no papel e de algumas articulações, o primeiro slam do país acontece, ainda que de forma improvisada, sua primeira edição ficou lotada e teve uma recepção positiva por parte do 
público presente. Durante o processo de criação do ZAP!, Roberta precisou entrar em contato com diferentes pessoas para conseguir realizar o evento. "Eu sou meio cara de pau, acho que é do signo também, eu sou aquariana. Você vai indo, indo, indo."

Aqui no Brasil os slams acontecem nas ruas em sua maioria, e isso se tornou uma marca nacional, o desejo de ocupar os espaços públicos. Além disso, outra característica marcante é o romper com o conceito de batalhas de poesia e se tornar um movimento de resistência das favelas e periferias. Os slams se inserem num amplo contexto de produções culturais e artísticas que acontecem nas regiões periféricas da cidade, onde historicamente se têm percebido as ausências e falhas de equipamentos do poder público no atendimento às demandas das populações. Esses movimentos de slam estão se convertendo em novos espaços de sociabilidade em que se busca, através da poesia e da arte, questionar a realidade desses jovens.

O movimento tem se espalhado ao redor do mundo e mesmo com tamanha proporção, ainda assim, guarda um caráter local e suas regras podem mudar de acordo com a localidade. A localidade tem um papel fundamental, pois é a partir dela que questões importantes surgem, como a identidade, o nome e o grito desse slam. O nome é dado pelo grupo responsável pelo slam, no Brasil temos como exemplos o Slam das minas (RJ), Slam Resistência (SP), Slam da Quentura (CE) e assim os nomes vão mudando de acordo com as escolhas dos grupos. Além disso, o grito é algo que afirma a identidade daquele lugar onde acontece o slam, cada grupo tem o seu e essa fala é sempre feita antes de alguma apresentação pelo apresentador com a interação do público presente.

É preciso compreender que o fortalecimento do movimento de slams do país é o ponto principal de sua construção. Pois é através do afeto do grupo que as tarefas conseguem fluir, pois o trabalho é feito sem nenhum tipo de apoio financeiro.

\section{SLAM LAJE - O SUBALTERNO TEM VOZ!}

Meu primeiro contato com o Slam Laje aconteceu em abril de 2018, através de alguns interlocutores que havia conhecido, em 2016, durante uma residência oferecida pelo coletivo GatoMídia ${ }^{2}$ no Complexo do Alemão. O desejo de compreender que juventude

\footnotetext{
${ }^{1}$ Fala presente na matéria “A Roberta Estrela D'Alva tem um papo pra te dar”, publicada no site Vice em 19/09/2016. Disponível em: https://www.vice.com/pt br/article/avakgj/conheca-roberta-estrela-dalvaavon-femme

${ }^{2}$ O coletivo GatoMídia propõe uma formação em conjunto nas ferramentas de mídia alternativas como por exemplo facebook, youtube, twitter e instagram. Nas quais é feita uma cobertura colaborativa e são dados “macetes" para potencializar esses recursos e gerar visibilidade para seu projeto, trabalho ou causa. É um
} 
está presente e faz parte dessa comunidade me motivou a fazer uma imersão nessa residência oferecida pelo GatoMídia. Essa residência durou duas semanas, com oficinas teóricas e práticas. Na residência conheci Sabrina Martina, que atualmente é conhecida como MC Martina, ela é uma das idealizadoras do Slam Laje. Sua participação em organizações de movimentos sociais não se resume apenas ao slam, atualmente ela se divide nas funções de Produtora Cultural e Poeta além de estudante, pois deseja passar no vestibular para o curso de ciências sociais.

Assim como outros slams que acontecem em territórios periféricos, o Slam Laje começou no morro do Alemão, na laje da Casa Brota, essa casa é o primeiro espaço de coworking para empreendedores de favela com o objetivo de ser um ponto de encontro para trocas de ideias e projetos relacionado à inovação, tecnologia, ao entretenimento e engajamento. Segundo MC Martina, a escolha de uma laje se deu pelo fato da polícia ocupar o morro e o fato de acontecer em alguma rua da comunidade a PM poderia agir de forma mais bruta ou até mesmo impedir que o evento acontecesse.

Acompanhei a edição de aniversário de um ano do Slam Laje no mês de maio do ano de 2018, a previsão de início do evento seria às $15 \mathrm{~h}$, na praça Verde em frente à sede da ONG Raízes em Movimento ${ }^{3}$, na Avenida Central no Complexo do Alemão. Apesar da greve dos caminhoneiros que acontecia nas rodovias do país, as pessoas não deixaram de ir ao evento para recitar e ouvir poesias. A mestra de cerimônia foi Carol Dall Farra, que é também poeta e rapper e estudante de Geografia pela UFRJ. Nesse dia, Dall Farra iria comandar o Slam Laje, diferentemente das outras edições que contava com outro apresentador, ela assume o comando do microfone do aniversário de 1 ano do Slam.

Na praça, Sabrina explica a dinâmica dessa edição de aniversário, pois não se faz nada sozinho e a ajuda e apoio que ela tem recebido tem sido fundamental para a continuidade do evento. Ela apresenta o novo formato que vai ser o Slam a partir daquela data, pois ali iniciava uma ação itinerante devido a uma necessidade de circular a favela. As edições anteriores do Slam Laje aconteciam na laje da Casa Brota, agora através desse novo

projeto de convivência e aprendizado em mídia e tecnologia para jovens de espaços populares, que existe desde 2013 no complexo do alemão, tendo como objetivo estimular que jovens e negros possam produzir sua própria comunicação, rede e conexões. Possibilitando diferentes narrativas, visibilidade, oportunidades e ideias criativas coletivas que construa um mundo mais justo, igualitário e afetivo.

3 O Instituto Raízes em Movimento é uma Organização não governamental que surgiu em outubro de 2001, no Complexo do Alemão, a partir de um grupo formado por jovens e universitários moradores da área e pessoas envolvidas em trabalhos sociais na região. Inicialmente o grupo contabilizou as potencialidades e recursos existentes - materiais, humanos e articulações - para traçar as primeiras estratégias de atuação. As primeiras atuações do grupo foram: trabalhar a questão ambiental, promover atividades esportivas e ações para a educação e cultura, além da capacitação constante de seus integrantes para o fortalecimento institucional. 
formato o evento iria realizar parcerias com outros espaços e ONGs no intuito de circular o Slam Laje pelo Complexo do Alemão.

Essa parceria com a Ong Raízes em Movimento, tem o objetivo de fortalecer esses espaços e trazer um novo público para conhecê-los. Essa edição, por ser em uma data especial, presentearia o vencedor com um corte de cabelo com o Al Neg que é poeta e produtor do slam laje, e barbeiro e tem um salão no Alemão. Além do corte, havia camisas da Ong Raízes e do Slam, livros, e o mais importante, que seria a vaga na final. Nesse evento, ao invés de se classificar apenas o primeiro lugar, seria dada a vaga também ao segundo lugar.

Através do grito "A favela está passando a mensagem, SLAM LAJE! - Abra seu coração!”, a apresentadora inicia a programação, para começar o microfone é aberto ao público presente para declamar suas poesias antes da batalha oficial. Nessa espécie de aquecimento, (a/o) s poetas(x) que deram seus nomes a apresentadora podem recitar seus versos e os que ainda não se inscreveram para a batalha podem também se inscrever. Durante as apresentações fui completamente tocado pelos versos da Negra Rê, a primeira poeta a se apresentar. Ela, além de poeta, é vendedora e tem um brechó, sendo conhecida no Slam laje por estar sempre presente vendendo suas roupas e seus brownies, "que tem um toque especial de quero mais".

Nessa edição, ela resolveu fazer uma homenagem a sua amiga e poeta Thaina Denicia, conhecida como Thai Flow, que estava hospitalizada, Negra Rê fala da sua amizade com Thaina e da forma como ela admira a força dessa mulher que mesmo tão jovem tem alcançado muitas pessoas. "Existe uma entre tantas que se chama Thaina, ela é livre, é plena e é problema de raiz”" entre lágrimas ela declama sua poesia e ao final pede que todos façam orações pela Thaina, para que ela passe por esse momento de fragilidade. A mestre de cerimônia reitera que caso estivesse bem Thai Flow seria uma das convidadas daquela edição do slam.

O evento segue com sua programação e outros poetas fazem suas apresentações no microfone aberto, antes que as batalhas se iniciem. O próximo a se apresentar foi o rapper e poeta W-black, que é um dos responsáveis pelo Slam Resistência que acontece no bairro de Vila Isabel, ele declamou a letra de sua mais nova música "Quem mata mais?”. O rapper traz em sua letra a luta que precisa enfrentar constantemente pelo fato de ser negro e a constante disputa que precisa fazer para sobreviver dentro de uma sociedade que cada vez mais estigmatiza os jovens, principalmente negros de periferia.

Encostado na parede e mãos no meu bolso, voltei à escravidão sensação de calabouço. 'Passa a droga, anda logo otário' Meu bolso tá vazio eu 
nem sequer sou usuário. 'Documento, por favor', Ficou sem ação, quando mostrei a carteirinha do mestrado em educação. O sistema dá pane quando vem pra opressão e encontra preto e pobre que tem pósgraduação. (W-BLACK, 2018)

Esse tipo de poesia se torna cada vez mais comum dentro do slam, pois, os poetas veem aquele momento além de um acontecimento poético, mas um movimento social para refletir a realidade vivida por cada jovem que tem tido sua juventude e identidade negadas.

Juarez Dayrrel apresenta, a partir de uma visão antropológica, a necessidade de se considerar a posição social desses jovens e o tratamento que lhes é dado, pois se tornam experiências diversificadas através de contextos históricos e culturais diversificados.

$\mathrm{Na}$ visão hegemônica sobre a juventude, por exemplo, a primeira postura se manifesta na compreensão do jovem como um vir a ser, tendo, no futuro, na passagem para a vida adulta, o sentido de suas ações no presente. (...) Alia-se a uma tendência em determinar o tempo da juventude com critérios etários predefinidos e rígidos, delimitando posturas e políticas públicas que não atendem às necessidades da juventude. (DAYRELL, 2004, p. 2)

Para o autor, em nossa sociedade há uma cobrança em relação a que caminho o jovem cidadão vai seguir e, qualificando esses jovens através de faixa etária ou de uma postura específica, essa sociedade iria encarar os jovens moradores de favelas e territórios periféricos através de um olhar negativo, aquilo que são e que não alcançaram. Além disso, outras questões permeiam esses jovens, principalmente os que vivem nas periferias das cidades, como o fato de não ter o cabelo liso dentro dos "padrões" construídos de beleza ${ }^{4}$, considerado como certo, ou através da ausência de roupas com logomarcas de grifes, em constante disputa, do que é considerado moderno ou atual para a nossa sociedade.

Seguindo a apresentação do W-black, uma criança traz sua poesia para se apresentar, Leticia é "cria" do slam, esse termo é bastante utilizado quando você mora em algum lugar há muito tempo, conhece as pessoas e com isso se torna popular. Ela está sempre presente no Slam Laje, acompanhada de sua mãe e de seu irmão, me chamou a atenção o fato de Leticia, que tem apenas oito anos e está no terceiro ano do ensino fundamental, estar nesse lugar de poeta no microfone aberto pois as demais crianças costumam participar da batalha do passinho que acontece em dois momentos do evento, no meio das batalhas e depois da batalha final.

Acompanhada de seu livro, ela inicia sua poesia de forma tímida, "viver é uma aventura, esse é o nosso ponto de partida", durante a apresentação a entonação muda e é possível

\footnotetext{
4 A escritora Grada Kilomba na obra Memórias da Plantação retrata os meandros do racismo cotidiano relatado por mulheres negras e nos convida a pensar e repensar sobre de onde surgem esses "padrões", sobre racismo, sobre colonialismo, sobre alteridade, sobre conhecimento e linguagem:
} 
perceber a força que ela tem, força que contagia o público ali presente, mas se torna timidez ao finalizar o poema.

Durante a programação do evento, o microfone também fica disponível para que aquele que estiver ali entre o público e queira divulgar seus eventos ou realizar convites ter a oportunidade de fazê-lo. Naquela ocasião, um dos produtores de uma mostra de filmes que aconteceria no bairro de Madureira fez questão de convidar aqueles moradores para estarem presentes no evento, pois lá teriam discussões sobre diversos temas que abordam não só a temática da favela, mas transfobia e feminismo, além disso, reforçando a importância da favela "descer" e ocupar todos os espaços públicos da cidade.

A sequência da apresentação no microfone aberto recebeu a participação da poeta Lúdica, ela faz parte de um grupo de rap junto com outras meninas, chamado Nefertaris Vandal, na ocasião a poeta reforçou que diferentemente dos espaços brancos em que ela circula a favela a recebe com afeto. Além disso, Lúdica dedicou sua apresentação para as crianças negras ali presentes. Na poesia a mensagem passada era sobre como cuidar das crianças em um ambiente de violência, como preservar a vida do inocente.

Eu ouço um pá, pum. Mais um grito de desespero de uma criança tão comum. Mais uma criança que se vai nessa cidade aqui, mas quem é que se importa ou vai comprar briga aí. Mais um caso largado e uma criança vestindo a camisa do Estado. (...) Mais uma bala perdida e um coração em desespero, mais uma mãe chorando aqui no Rio de Janeiro. Mais uma bala perdida direto de um fuzil e na hora da justiça ninguém viu.

(LÚDICA, 2018)

A participação do público durante a apresentação de Lúdica me chamou a atenção, aqueles que estavam ali presentes começaram a interagir com a mesma repetindo parte da poesia que dizia: "cuidado com a criança negra, cuide de uma criança negra. Não tem culpa dessas tretas, são crianças, são cristais".

Os(a/x) poetas $(x)$ encontram no slam um espaço para refletir sobre o que os têm tocado, sobre suas incertezas, seus medos e desejos para o futuro. Suas falas são atravessadas por suas experiências e muitas vezes pela forma como a poesia transformou sua vida. Anzaldúa (2000) fala sobre esse recurso da escrita que ajuda a sobreviver.

A escrita é uma ferramenta para penetrar naquele mistério, mas também nos protege, nos dá um distanciamento, nos ajuda a sobreviver. E aquelas que não sobrevivem? Os restos de nós mesmas: tanta carne jogada aos pés da loucura ou da fé ou do Estado. (ANZALDÚA, 2000, p.232).

\footnotetext{
${ }^{5}$ A expressão "descer" da favela nesse contexto apresenta a importância desses corpos que vivem dentro desse território, saírem de suas comunidades e ocuparem a cidade para além de seus bairros, ocupando espaços que não aceitam seus corpos e suas identidades.
} 
Em sequência a performance de Lúdica, foi a vez do poeta Ian se apresentar, no último slam que eu estive presente o poeta se apresentou e fez uma homenagem a sua avó. Tenho percebido que os homens que se apresentam nos slams que tenho frequentado, quando colocam a figura da mulher em seus textos elogiam a figura materna ou a força dessa mulher em criar os filhos sozinhos, diferentemente das mulheres que quando falam sobre os homens em sua maioria é para expor assédios e abusos.

Uma das últimas pessoas a se apresentar no microfone aberto foi uma moça chamada Juliana, ela estava com a sua filha e disse que aquela era a primeira apresentação dela e que apesar de frequentar o slam nunca tinha coragem de competir ou recitar sua poesia e que aquele momento seria "a primeira vez" que ela iria soltar a sua voz. Juliana reforça o fato de se sentir em casa no slam, em sua poesia ela reforça o quanto foi ofendida sendo chamada de gorda e favelada, mas reforça que mesmo ofendida jamais ficou abatida. Para a autora Gayatri Spivak, para que seja mantida esta relação de poder, a força maior tende a inferiorizar a menor força por meio da violência física ou epistêmica.

A pessoa que fala e age (...) é sempre uma multiplicidade", nenhum 'intelectual teórico (...) [ou] partido ou (...) sindicato' pode representar 'aqueles que agem e lutam' (FD, p. 206). São mudos aqueles que agem e lutam, em oposição àqueles que agem e falam? (SPIVAK, 2010, p.32).

Após o final dessa primeira parte do evento, é aberta a fase de competições e nessa edição de comemoração do primeiro aniversário do Slam Laje foram disponibilizadas 2 vagas para a final. A presença masculina na competição era mínima perto das candidatas ao título de Campeã daquela edição. As falas femininas eram marcadas pela força e muitas vezes como um protesto contra os abusos ou assédios sofridos. A poeta Jaqueline Alves apresentou uma poesia para sua amada, diferentemente do que estava ouvindo até então, a poesia falava de amor e como havia uma conexão entre as duas. ${ }^{6}$

Sabrina é ritmo frenético, pulsação acelerada andar descompassado sentimento acalentado sorriso de lado abraço apertado olhar fixado é sexo exagerado. Nossos corpos úmidos e unidos se transformam em correntezas que ultrapassam as fronteiras e que quebram qualquer barreira contemplo cada partícula do teu ser, tua boca pede, me bebe, me excita, alucina Martina. Menina inexplicavelmente fascinante és minha amante, és delirante, amo seu jeito incessante de ocupar a minha vida, amo ser amada, ser desejada, ser amparada. Sá, brilha no meu céu estrelado, vem cá me dá mais um bocado das suas juras apaixonantes, das suas invenções alucinantes minha paixão queima igual fogueira quando se entrega por inteira além do físico material quando me toca me teletransporta para o espaço sideral. A leveza de seus dedos causam arrepios que levantam e entrelaçam todos os meus fios és parte de mim

\footnotetext{
${ }^{6}$ A transcrição da poesia de Jaqueline Alves foi realizada posteriormente ao evento através dos vídeos que registraram a apresentação. Disponível em: https://www.facebook.com/batalhadepoesia/videos/169970650343466/ Acessado em 02/06/2020.
} 
mi amor. Só não seja uma parte repartida quero que seja uma parte cognitiva assim tão conectada será sempre minha parte mais amada. (ALVES, 2018).

Após três rodadas de batalhas são anunciados os dois finalistas que já possuíam suas vagas reservadas para a grande final do Slam Laje que vai decidir quem será seu representante na competição estadual. Os poetas vencedores da edição foram Sabrina Azevedo e Dudu Neves, os dois participam do mesmo coletivo, Nós da Rua ${ }^{7}$ que foi criado em abril de 2017 na favela da Cidade de Deus em Jacarepaguá e visa trazer literatura e poesia para a zona oeste do estado do Rio de Janeiro através de eventos de integração com as comunidades da região, através do slam e de oficinas.

Durante a apresentação da finalista Sabrina Azevedo, é possível perceber um jogo de entonações, sua interpretação dos versos é as vezes agressiva e irônica. É como se seu corpo falasse além das palavras que saiam de sua boca, mas também através do caminhar de um lado para o outro. Segundo Paul Ricoeur (1997), “o simbolismo confere à ação uma primeira legibilidade", esse entendimento da simbólica ajuda na interpretação dos gestos e ações de cada poeta, que pode gerar no público uma expectativa em como essa apresentação será feita.

Sabrina foi a primeira colocada e, em suas poesias, o feminismo e o racismo eram os temas mais abordados, "Meus heróis não morreram de overdose, morreram assassinados.". $\mathrm{Na}$ última rodada o júri foi unanime em dar a essa poesia a maior nota daquela edição, o tão desejado 10, e que garantiu a primeira colocação do Slam Laje.

A programação segue após o anúncio da apresentadora de como ficou a colocação final e chega a hora das crianças batalharem. Uma parte de sua programação é reservada para a batalha do passinho, as crianças que participam ganham chocolates ou doces, isso depende do que a organização do slam vai conseguir de doação para poder comprar os brindes.

Essa seria uma maneira de trazer um outro público para o slam, pois as crianças se divertem dançando e no final ainda ganham um brinde ou doce. Durante sua programação, tem um momento em que passa um chapéu para que seja feita uma colaboração, pois o evento é totalmente independente e não recebe um auxílio financeiro que ajude na realização do slam. O Encerramento é feito após a batalha do passinho ao som de muito Funk e o sorriso no rosto por mais uma edição ter sido realizada com sucesso.

O slam se torna um lugar onde há um encontro de múltiplas identidades, e é nesse lugar que as pessoas se reúnem para compartilhar palavras, ideias, poemas. Manuel Castells

${ }^{7}$ Página do coletivo Nós da Rua. Disponível em: https://www.facebook.com/nosdaruapoesia/ 
afirma que identidade é "fonte de significado e experiência de um povo" (2002, PAG 22), a partir dessa definição o autor três tipos de identidades: identidade de resistência, identidade de projeto e a identidade legitimadora. Castells afirma que a identidade de resistência é a que proporciona a formação de comunidades e que essa razão seria a mais importante para a construção de identidades em nossa sociedade.

A pesquisadora Aline Sabino reforça a necessidade de uma luta desses corpos para afirmar suas identidades e se fazer presente em espaços que lhes são negados. Segundo Sabino, (2017, PAG 113) "o slam condensa poetas marginalizados, que lutam por reconhecimento e mudança social através da arte. São corpos que procuram estar em espaços, que lhes são negados". O poeta favelado está inserido em um território que é repleto de negações, sua vida é uma completa disputa para afirmar sua existência e sua identidade. É preciso compreender como ocorre o processo de resistência e sobrevivência por parte desses jovens dentro de uma favela.

Walter Benjamin fala sobre a experiência como fonte para o narrador, podemos relacionar essa como a fonte principal dos poetas que vão se apresentar no slam. Além disso, a relação desses sujeitos com a memória é muito forte, esses ensinamentos, essas experiências se tornam conteúdos para as suas poesias. Esses jovens de fato vivenciam suas experiências e as compartilham dentro dos slams.

A experiência que passa de pessoa a pessoa é a fonte a que recorrem todos os narradores. E, entre as narrativas escritas, as melhores são as que menos se distinguem das histórias orais contadas pelos inúmeros narradores anônimos. (BENJAMIN, 1994, p.198)

Diferentemente do silenciamento que os sobreviventes traziam após seu retorno da guerra, os poetas fazem de suas guerras e lutas contra a homofobia, o racismo, o machismo, poesias e tem colocado no papel suas inquietações.

Esse movimento cultural se manifesta em um cenário mais amplo, que se denominou no presente trabalho como campo literário marginal periférico, pois os estudos sobre literatura marginal e saraus periféricos (NASCIMENTO, 2006) apontam que essas manifestações culturais criadas entre o fim da década de 1980 e ao longo dos anos 1990, podem servir como uma base para outros desdobramentos culturais, já que além da promoção de atividades culturais eles reorientam a própria visão do que é periferia e marginalidade.

\section{CONSIDERAÇÕES FINAIS}


A proposta desse trabalho foi refletir sobre a relação dos jovens poetas de periferia junto das novas narrativas que estão surgindo através do movimento de slams, de forma que esses jovens se utilizam desses espaços para afirmar suas identidades e falar sobre suas experiências pela cidade. Embora os slams tenham experimentado um rápido crescimento e popularização por todo o país nos últimos anos, ainda há muito o que se pesquisar sobre o tema e poucos são os estudos sobre as implicações dessas práticas em nossa sociedade.

Os slams possibilitam o afeto e a potência da favela na cidade, além da ocupação de espaços públicos através de intervenções urbanas e capazes de proporcionar encontros de pessoas em processos de troca de conhecimento e experiências. Através desse movimento, passou-se a repensar o papel do artista da periferia em relação a sua comunidade e do indivíduo em relação à arte, seja como produtor ou espectador de intervenções. A própria ideia de que todo indivíduo é capaz de emitir uma opinião válida sobre arte, não necessitando de uma formação acadêmica ou técnica na escolha dos jurados, reforça essa questão. No entanto, é preciso ressaltar que apesar de alguns poetas receberem visibilidade e circularem a cidade através da sua arte, que há um longo caminho para que haja um espaço próprio de circulação e divulgação destes poemas e poetas para fora do círculo dos slams e públicos de suas comunidades.

Menosprezar a questão das diferenças culturais, a partir de um entendimento próprio do que é cultura, seria como aceitar de um modo geral e sem maior questionamento, que ela designava o conjunto de tudo àquilo que a humanidade havia produzido de melhor através de materiais artísticos, filosóficos, literários etc.

Não podemos negar desde já os avanços feitos e a relevância do tema para a pesquisa acadêmica e para os debates culturais que se preocupem com o empoderamento de grupos subalternos, das margens de nossa sociedade. Nos combates de poesia convergem, nas ruas, as batalhas que estes jovens travam cotidianamente para garantir seu direito de existir e resistir.

Há uma ressignificação de termos considerados negativos em nossa sociedade, como favelados, na qual esse sentido se torna identidade e motivo de orgulho. Mesmo sendo considerados "os outros", esses jovens se apropriam dos bens e dos espaços que lhes são muitas vezes negados pela cor, pela condição financeira, pelo gênero, entre outros motivos, e encontraram alternativas para mostrar os seus corpos vivos dentro da sociedade, a poesia se tornou uma ferramenta para afirmar essa identidade.

É preciso ampliar o olhar para a cultura presente nas favelas, pois esse território possui uma grande riqueza dentro da cidade, é a mistura de arte com a vida que faz a 
esperança de viver sua rotina ser chamada de cultura. Apesar de seus problemas estruturais, é possível compreender que há o desenvolvimento de uma arte diversificada e muitas vezes incompreendida, tais questões apresentam a potencialidade desse espaço popular desmistificando todo um conceito baseado em falta de recursos e carência social.

Recebido para publicação em 13 de maio de 2020.

Aceito em $1^{\circ}$ de agosto de 2020.

\section{REFERÊNCIAS}

ANZALDÚA, Gloria. Falando em línguas: uma carta para as mulheres escritoras do terceiro mundo. Revista Estudos Feministas, Florianópolis, v. 8, n. 1, p. 229, jan. 2000. ISSN 1806-9584. Disponível em: <https://periodicos.ufsc.br/index.php/ref/article/view/9880/9106>. Acesso em: 28 set. 2018.

BENJAMIN, Walter. "O narrador". In Magia e técnica, arte e política. São Paulo, abril, 1983.

CARDOZO, Viviane Laprovita. Novas possibilidades literárias: slams de poesia invadem a cidade e propagam a voz das periferias. In: ENECULT - Encontro de Estudos Multidisciplinares em Cultura, 2018, Salvador - BA.

CASTELLS, Manuel. O poder da Identidade. In A era da informação: economia, sociedade e cultura, v. 2. Tradução Klauss Brandini Gerhardt. São Paulo: Paz e Terra, 2002

D’ALVA, Roberta Estrela. Um microfone na mão e uma ideia na cabeça - O poetry slam entra em cena. 2011. Disponível em <http://gerflint.fr/Base/Bresil9/estrela.pdf>. Acesso em 20 set. 2018.

DAYRREL, Juarez. Juventude, grupos culturais e sociabilidade. Faculdade de Educação da UFMG/ Observatório da Juventude da UDMG, 2004.

GAMA, Danielle. Slams: batalhas de poesia e a obra literária - reflexões a partir do pensamento de Pierre Bourdieu. In: ENECULT - Encontro de Estudos Multidisciplinares em Cultura, 2018, Salvador - BA.

KILOMBA, G. Memórias da Plantação: episódios de racismo cotidiano. Rio de Janeiro: Cobogó, 2019.

MOURA, M. M. Língua, cultura e Slam: traduzindo poemas para o II Rio Poetry Slam. Revista Versalete, v. 4, p. 1-246, 2016

NASCIMENTO, Érica Peçanha do. "Literatura marginal": os escritores da periferia entram em cena. 2006. Dissertação (Mestrado) - Faculdade de Filosofia, Letras e Ciências Humanas. Universidade de São Paulo (USP). São Paulo 
NEVES, C. Slams - letramentos literários de reexistência ao/no mundo contemporâneo. Linha D’Água, v. 30, n. 2, p. 92-112, 27 out. 2017.

RIBEIRO, Djamila. O que é: lugar de fala? Belo Horizonte (MG): Letramento, 2017.

RICOEUR, P. Tempo e narrativa. Campinas, Papirus, p. 327. 1997.

SABINO, Maria Aline. Performance e aprendizagem no slam da quentura em Sobral, Ceará. 2017. 74 f. Trabalho de Conclusão de Curso - Centro de Ciências Humanas, Universidade do Estado do Vale do Acaraú, Ceará, 2017.

SPIVAK, Gayatri. Pode o subalterno falar?. Belo Horizonte, UFMG, 2010.

W-BLACK. Quem Mata Mais? Disponível em: https://www.youtube.com/watch?v=zid4VcqgddI , 23/03/2018. Acesso em: 24/09/2018. 


\title{
“THE FAVELA IS PASSING THE MESSAGE" - CONSTRUCTIONS OF NEW NARRATIVES IN COMPLEXO DO ALEMÃO
}

\begin{abstract}
This article aims to reflect on the construction of new narratives within the complex of favelas in Complexo do Alemão and the way this construction affects poets and consequently the public present in the slam. I seek to present the Slam Laje that has been taking place in Alemão through my experience in the field that took place on the 1st year anniversary of the event. Slam is a new phenomenon of oral poetry and through its performance it has been gaining space throughout the country, through its battles the poets of the favela are sending the straight talk talking about racism, homophobia and feminism seeking reflection by the public. In this work, some concepts of identity and representativeness will be analyzed based on studies by Gloria Anzaldúa, Gayatri Spivak and Walter Benjamim.
\end{abstract}

Keywords: Slam; Favela; Youth; Poetry.

\section{“LA FAVELA ESTÁ PASANDO EL MENSAJE” - CONSTRUCCIONES DE NUEVAS NARRATIVAS EN COMPLEXO DO ALEMÃO}

Resumen: Este artículo propone reflexionar sobre la construcción de nuevas narrativas dentro del complejo de favelas en Complexo do Alemão y la forma en que esta construcción afecta a los poetas y, en consecuencia, al público presente en el slam. Intento presentar el Slam Laje que ha tenido lugar en Alemão a través de mi experiencia en el campo que se llevó a cabo en el primer aniversario del evento. Slam es un nuevo fenómeno de poesía oral y, a través de su actuación, ha ido ganando espacio en todo el país, a través de sus batallas, los poetas de la favela están enviando una conversación directa sobre el racismo, la homofobia y el feminismo buscando la reflexión del público. En este trabajo, se analizarán algunos conceptos de identidad y representatividad basados en estudios de Gloria Anzaldúa, Gayatri Spivak y Walter Benjamim.

Palabras claves: Slam; Favela; Juventud; Poesía.

Natã Neves do Nascimento - Mestre em Cultura e Territorialidades pelo Programa de Pós-Graduação da Universidade Federal Fluminense (UFF), com o projeto de pesquisa Três minutos, duas mãos e uma voz: Performances, Trajetórias e Sobrevivências através de batalhas de poesias sob orientação da professora Dra. Adriana Facina. Possui graduação no curso de Produção Cultural da Universidade Federal Fluminense concluída no ano de 2016. Pesquisou os Jovens que moram em favelas, suas dinâmicas identitárias e culturais além de desmistificar estereótipos presentes nesse território. 